\title{
Project ACCLAIM: Intervention Effect on Community Knowledge, Attitudes and Beliefs of Maternal and Child Health and HIV/AIDS in Eswatini, Uganda and Zimbabwe
}

\author{
N. Bandopadhay ${ }^{1}$ - G. B. Woelk ${ }^{2}$ (D) M. P. Kieffer ${ }^{2}$ - D. Mpofu² · the Project ACCLAIM Study Group $3,4,5$
}

Accepted: 14 February 2021 / Published online: 4 March 2021

(c) The Author(s) 2021

\begin{abstract}
The ACCLAIM Study aimed to assess the effect of a package of community interventions on the demand for, uptake of, and retention of HIV-positive pregnant/postpartum women in maternal and child health (MCH) and prevention of motherto-child HIV transmission (PMTCT) services. The study occurred from 2013 to 2015 in Eswatini, Uganda, and Zimbabwe. The three interventions were: (1) a social learning and action component for community leaders, (2) community days, and (3) peer discussion groups. Household cross-sectional surveys on community members' MCH and PMTCT knowledge, attitudes, and beliefs were analyzed pre- and post-intervention, using MCH, HIV stigma, and gender-equitable men (GEM) indicators. We used t-tests to measure the significance of mean pre- vs. post-intervention score changes stratified by gender within each intervention arm and generalized linear models to compare mean score changes of the cumulative intervention arms with the community leaders-only intervention. Response rates were over $85 \%$ for both surveys for men and women, with a total of 3337 pre-intervention and 3162 post-intervention responses. The combined package of three interventions demonstrated a significantly greater increase in $\mathrm{MCH}$ scores for both women $(\operatorname{diff}=1.34, \mathrm{p} \leq 0.001)$ and men $(\operatorname{diff}=2.03$, $\mathrm{p}<0.001$ ). The arms that included interventions for both community leader engagement and community days (arms 2 and 3)led to a greater increase in mean GEM scores compared to the community leader engagement intervention alone (arm 1), for both women ( $\operatorname{diff}=1.32, \mathrm{p}=0.002)$ and men ( $\operatorname{diff}=1.37, \mathrm{p}=0.004)$. Our findings suggest that a package of community interventions may be most effective in increasing community MCH/HIV knowledge and improving gender-equitable norms.
\end{abstract}

Keywords HIV/AIDS $\cdot$ Maternal and child health $\cdot$ PMTCT $\cdot$ KAB $\cdot$ HIV stigma $\cdot$ Gender $\cdot$ Community interventions

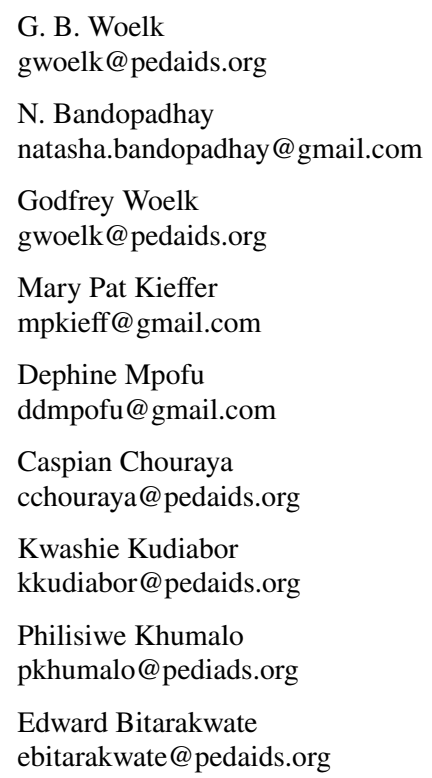

Eliab Natumanya Kajungu ekajungu@pedaids.org

Agnes Mahomva mahomvaagnes@gmail.com

Reuben Musarandega rmusarandega@pedaids.org

1 Milken Institute School of Public Health George Washington University, Washington DC, USA

2 Elizabeth Glaser Pediatric AIDS Foundation, 1140 Connecticut Ave NW, Suite 200, Washington D.C. 20036, USA

3 Elizabeth Glaser Pediatric AIDS Foundation, Mbabane, Eswatini

4 Elizabeth Glaser Pediatric AIDS Foundation, Mbarara, Uganda

5 Elizabeth Glaser Pediatric AIDS Foundation, Harare, Zimbabwe 


\section{Introduction}

Innovative approaches are needed to eliminate mother-tochild HIV transmission (MTCT) in high-burden (priority) countries. With the adoption of universal treatment for people living with HIV in most countries, including for pregnant women, 6-week MTCT rates have fallen dramatically in the 21 priority countries, declining from 28\% [25-30\%] in 2009 to $14 \%$ [12-16\%] in 2014 [1]. However, 160,000 children were newly infected with HIV in 2018 [2]. Significant barriers remain that are not specific to HIV and that interfere with uptake of HIV treatment among pregnant women. These barriers include inequitable gender norms, HIV-related stigma, and inadequate mother and child health $(\mathrm{MCH})$ knowledge [3-6]. Interventions to address these barriers have included community health promotion and education activities, and engagement strategies $[4,7]$. However, many of these approaches focus on increasing knowledge, with insufficient attention paid to attitudes and norms; which is necessary to enable sustainable behavior change at the community level [8]. In addition, barriers to prevention of mother-to-child HIV transmission (PMTCT) services are often interlinked; in that interventions which target both community and individual levels, may be more effective than interventions focused on one level. There are few examples of combined community-level interventions for PMTCT outcomes [9]. We tested an innovative community intervention package which included a social learning and action component (community leader engagement), community days (with community dialogues around selected $\mathrm{MCH}$ and PMTCT topics), and peer discussion groups, on the demand for, uptake of, and retention of HIV-positive pregnant/postpartum women in MCH/PMTCT services in Eswatini (formerly Swaziland), Uganda, and Zimbabwe from 2013 to 2015.

In this paper, we report on the effect of three interventions on MCH and PMTCT knowledge, attitudes, and beliefs (KAB) among community members in the study areas. This was a secondary analysis of the trial data focused on the community effects of the interventions. We assessed genderequitable norms, HIV-related stigma attitudes, and knowledge on maternal, neonatal, and childcare. We hypothesized that the three interventions together (community leader engagement, community days, and peer discussion groups) would result in the most significant increase in $\mathrm{MCH}$ beliefs and gender-equitable norms, as well as the most significant decrease in HIV stigma, when compared to the community leader engagement intervention alone for both women and men, when comparing pre- and post-intervention data.

\section{Methods}

\section{Study Design and Population}

The methodology of this multi-country, multi-component, three-arm randomized trial has been reported elsewhere [10]. In brief, in each of the three countries, three subunits (regions or districts) were identified, each consisting of 15 clusters (facilities) (Fig. 1). The regions or districts were then randomly allocated, one to each study arm. Arm 1 included the community leader engagement intervention, which involved identifying and training formal and informal community leaders to have dialogues with their community about MCH, HIV care, and PMTCT. Arm 2 included the community leader engagement intervention plus a community days intervention (i.e., community health fairs that combined service provision such as HIV testing, blood pressure screening, etc., with community dialogues about HIV issues, PMTCT, and HIV testing. Arm 3 included the community leader engagement intervention, the community days intervention, plus men's and women's peer discussion groups, where peer-led discussions provided information and education on $\mathrm{MCH}$ and PMTCT. The women's peer groups were held with women attending antenatal care (ANC); the men's groups included, but were not limited to, partners of the women attending ANC.

There was no control group, as there was already a high level of background community programming in the form of national PMTCT programs in study countries. The study team concluded therefore, that a true control group would be infeasible and unethical $[6,10]$.

In each country, Elizabeth Glaser Pediatric AIDS Foundation (EGPAF)-supported regions with no recent history of intensified community-level PMTCT interventions and low research activity but moderate to high maternal HIV yield were identified as potential intervention areas. The three subunits (one for each of the three study arms) were identified corresponding to the administrative structures (that is, regions or districts) existing in that country, also took into account the ability to implement interventions, with the support of the appropriate health authorities. In each of these districts/regions, five clusters (with a cluster defined as the lowest level of health facility that implements PMTCT services, together with its population catchment area [populations 7300-27,500]) were identified. Criteria for potential selection included recording at least $14 \mathrm{HIV}$-positive pregnant women in the most recent year, the smallest catchment population size, and catchment area completely within the district/region with no overlap, and mix of facility type. Referral facilities and urban facilities were excluded. All clusters meeting these criteria were selected. 


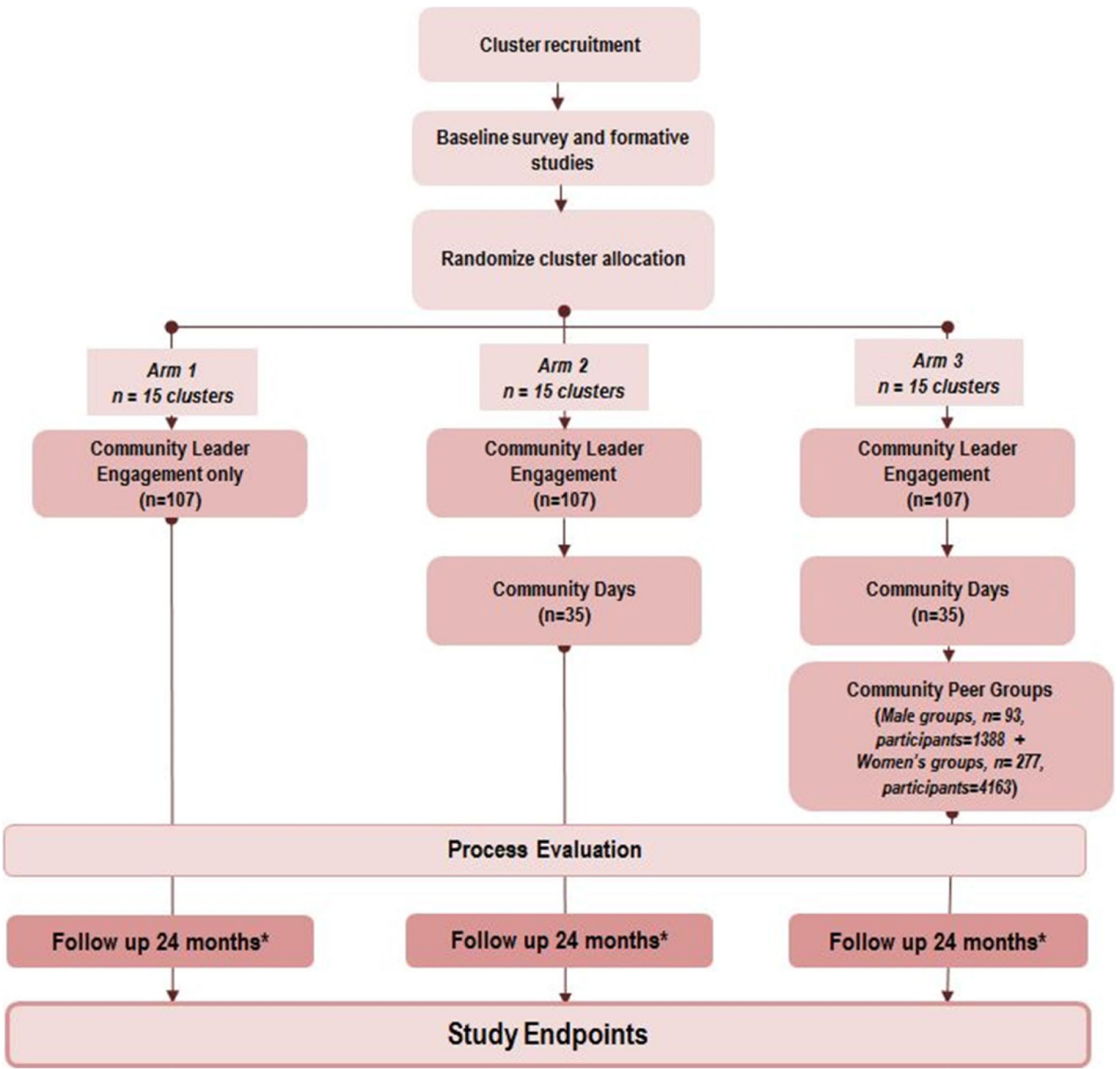

Fig. 1 Trial design. Reprinted from "Evaluating the effectiveness of selected community-level interventions on key maternal, child health, and prevention of mother-to-child transmission of HIV outcomes in three countries (the ACCLAIM project): a study protocol for a ran-

In order to assess potential changes in $\mathrm{MCH}$ knowledge, attitudes, and beliefs, we undertook pre- and post-intervention $\mathrm{KAB}$ cross-sectional surveys among women and men aged 18-60 years in randomly selected households in the selected clusters in each country. With the cross-sectional design, different households were likely to be selected pre- and post-intervention. One participant per household was selected. If there was more than one eligible participant per household, research assistants randomly selected domized controlled trial," by Woelk, G.B., Kieffer, M.P., Walker, D., Mpofu, D., Machekano, R., and the Project ACCLAIM study group. Trials, 17(88) 2016, p.5

a participant through a process involving the listing of all eligible participants. The randomization was based on sampling frames drawn from census lists and augmented by household lists or maps held by community leaders and/ or the relevant administrative offices. The surveys were enumerated by trained research assistants with appropriate supervision and the data were captured directly into an EPIINFO v7.1 database on laptop computers in the field. 
The survey was translated into the local languages (Runyankole, SiSwati, and Shona) and pre-tested.

\section{Survey Questions and Scoring}

The survey questions (statements) were drawn from items of validated scales and indicator compendiums of the Gender Equitable Men (GEM) Scale [11], the Tanzania Stigma Indicator and Community Baseline (Individual Questionnaire) [12], the World Bank Social Capital Assessment Tool (A-SCAT) [13], and the Rapid CATCH + 2009 Maternal and Neonatal Care Module [14]. The main outcomes for this analysis are MCH beliefs scores, (from the Rapid CATCH + 2009 Maternal and Neonatal Care Module), HIV stigma scores (from the Tanzania Stigma Indicator and Community Baseline (Individual Questionnaire), and the GEM norms scores. Table 1 shows an example of some of these questions.

The three outcome scores were numeric, and these outcomes were scored according to the scheme below:

$\mathrm{MCH}$ beliefs score: Responses to questions regarding $\mathrm{MCH}$ beliefs were scored based on a scale of 0-4; from "strongly agree" (4) to "strongly disagree" (1), and "neither agree nor disagree" ( 0 ) for true statements. False statements were reverse scored; "strongly agree" (1), to "strongly disagree" (4). Scores from each question were added up for each individual. A higher score indicated a better community understanding of $\mathrm{MCH}$ issues and a greater confidence in the community to address MCH-related HIV issues. For the pre-intervention surveys, Cronbach's alpha scores ranged from 0.31 to 0.48 across the three countries. For the post-intervention surveys, these scores ranged from 0.40 to 0.52 .

HIV stigma score: Responses to HIV-related stigma questions were scored 4-1; "strongly agree" (4) to "strongly disagree" (1). Scores for each question were added for each individual, with a lower composite score reflective of less HIV-related stigma. Cronbach's alpha scores ranged from 0.38 to 0.47 across the three countries for the pre-intervention surveys. For the post-intervention surveys, these scores ranged from 0.27 to 0.60 . Measuring HIV stigma was important, as other studies pointed out that HIV stigma is a key barrier to HIV prevention and treatment efforts [15].

Gender-equitable norms score: Scoring for the genderequitable norms section was based on the GEM Scale [11]. This section contained questions with statements that reflect gender inequitable norms. An "Agree" response was given a score of 1, "Partially agree" a score of 2 , and "Disagree" a score of 3. Scores for each question were summed to a composite score for each individual. A higher score was indicative of a higher degree of gender-equitable norms. Cronbach's alpha scores for the pre-intervention surveys across the three countries were $0.60-0.73$, and $0.64-0.75$ for the post-intervention surveys.

Out of several outcomes, these three scores were chosen because previous studies have failed to address community MCH support, HIV stigma within the community, and gender norms that affect women's participation in PMTCT programs [10]. In addition to these outcomes, the questionnaire consisted of items in the following areas: problems in accessing health care; individual MNCH knowledge, attitudes, perceptions and barriers; sexually transmitted infections; HIV

Table 1 Survey questions used for outcome scores

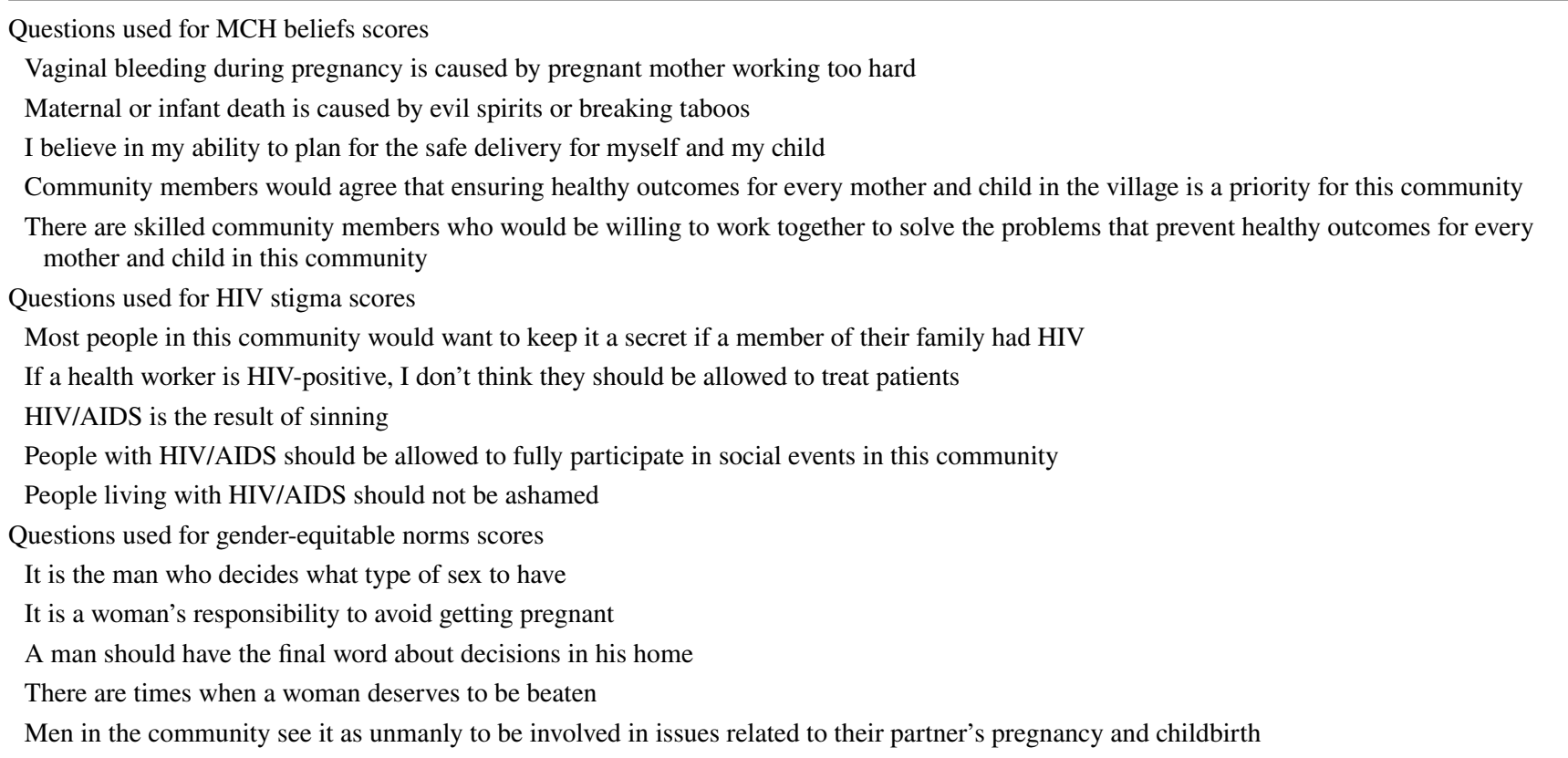


knowledge; HIV testing and disclosure; PMTCT knowledge; pregnancy and postnatal care (for women), GEM-equitable norms; household decision-making; contraception; and social capital (groups and networks).

We selected the three outcomes, as they were the most discriminant across the study arms and countries (data not shown). In addition, the outcome measures selected represent indicators of barriers and facilitators to PMTCT services. Factors that affect pregnancy outcomes overall are relevant for HIV-positive pregnant women. For example, the measure of "Vaginal bleeding during pregnancy is caused by pregnant mother working too hard" is an indicator of knowledge that working burden (working too hard) during pregnancy could result in a negative outcome of vaginal bleeding. The statement that maternal or infant death being caused by evil spirit or breaking taboos is a measure of superstition that is relevant for PMTCT as a belief that for example, death of an infant due to HIV could be because of evil spirits. The other MCH statements reflect a degree of self-efficacy and community cohesion; that a mother is able to act to have a successful birth outcome, and that the community members can work together to have healthy outcomes for mother and children, including PMTCT. Stigma is, of course, is a barrier to PMTCT, and so is gender inequity, where husbands for example, may be less supportive of their wives in pregnancy (especially for PMTCT), or unwilling to financially support women's attendance at ANC. These three outcomes were measured for both women and men, as previous studies did not assess men's attitudes in the community towards $\mathrm{MCH}$ support, which can affect women's health seeking behaviors and participation in PMTCT programs.

\section{Analysis}

We analyzed data by country and gender from the KAB community pre- and post-intervention surveys. Women completed 1783 pre-intervention surveys and 1807 postintervention surveys. Men completed 1554 pre-intervention surveys and 1355 post-intervention surveys. We tested the distribution of scores for MCH beliefs, HIV stigma, and GEM for normality. Mean MCH beliefs scores, HIV stigma scores, and GEM scores for each study arm were calculated from the pre-intervention surveys and the post-intervention surveys. T-tests were used to assess the difference between the mean pre-intervention scores and the mean post-intervention scores.

Although randomization was used for intervention assignment, descriptive data were compared for potential confounders across groups. The main potential confounders included age, highest level of education, number of years in the community, whether one is living away from home, source of income, and marital status.
We undertook a differences-in-differences analysis, comparing arms 2 and 3 against arm 1. We used generalized linear models with contrast analysis to test whether the postvs. pre-intervention mean score difference was significantly different in arms 2 and 3, compared to arm 1. A total of 6479 records were available for analysis. All analyses were undertaken using SAS 9.4.

\section{Results}

Response rates were over $85 \%$ for both surveys and men and women. Table 2 presents the demographic characteristics of the study participants.

The women in Zimbabwe were older (mean age 36.2 years), while those in Eswatini were younger (mean age 34.7 years). While men in Eswatini were the youngest participants, with a mean age of 33.9 years, Ugandan men were the oldest (mean age 39.8 years). The Zimbabwean women and men had higher levels of education, at $66 \%$ and $79 \%$, respectively, having attained secondary and above education. The Ugandan participants had the lowest education, at $20 \%$ of the women and $35 \%$ of men having secondary or more education. In Zimbabwe and Eswatini, participants tended to be Apostolic or Pentecostal Christian faiths, while the majority of Ugandan participants held more traditional Christian beliefs identifying as Protestant (Anglican) and Roman Catholic. Of note however, was that over $20 \%$ of Zimbabwean men reported having no religion.

Over $75 \%$ of the participants were long-term community residents ( $>5$ years). Around one-third of Zimbabwean participants, $32 \%$ of women and $39 \%$ of men, reported that they had been away from home for $>1$ month in the past 12 months, suggesting that they may have migrated for work. Over $75 \%$ of the Zimbabwean and Ugandan participants reported being married or living as married, as compared with $58 \%$ of women and $42 \%$ of men in Eswatini. Participants in Eswatini and Uganda came from larger households, (median household size 6). Among the Ugandan participants, $77 \%$ of women and $57 \%$ of men were engaged in farming as their main source of income. Only $31 \%$ of men and $25 \%$ of women in Eswatini farmed, while $37 \%$ of the women and $27 \%$ of the men received remittances.

Except for the gender equity score in arm 1 for men $(p=0.31)$, all the interventions led to improvements in scores for both men and women $(\mathrm{p}<0.01)$, as shown in Table 3.

The difference in mean indicator score changes by study arms for arms 2 and 3, compared to arm 1, is summarized in Table 4.

For both men and women, at least one of the combined intervention arms (2 and 3) resulted in improved $\mathrm{MCH}$ beliefs and GEM scores $(\mathrm{p}<0.05)$, compared with arm 
Table 2 Demographic characteristics of survey participants by country

\begin{tabular}{|c|c|c|c|c|c|c|c|c|}
\hline & \multicolumn{4}{|l|}{ Women } & \multicolumn{4}{|l|}{ Men } \\
\hline & $\begin{array}{l}\text { Zimbabwe } \\
\mathrm{n}=658\end{array}$ & $\begin{array}{l}\text { Uganda } \\
\mathrm{n}=556\end{array}$ & $\begin{array}{l}\text { Eswatini } \\
\mathrm{n}=549\end{array}$ & $\begin{array}{l}\text { Total } \\
n=1763\end{array}$ & $\begin{array}{l}\text { Zimbabwe } \\
\mathrm{n}=421\end{array}$ & $\begin{array}{l}\text { Uganda } \\
\mathrm{n}=584\end{array}$ & $\begin{array}{l}\text { Eswatini } \\
\mathrm{n}=552\end{array}$ & $\begin{array}{l}\text { Total } \\
\mathrm{n}=1557\end{array}$ \\
\hline & $\mathrm{n}(\%)$ & $\mathrm{n}(\%)$ & $\mathrm{n}(\%)$ & $\mathrm{n}(\%)$ & $\mathrm{n}(\%)$ & $\mathrm{n}(\%)$ & $\mathrm{n}(\%)$ & $\mathrm{n}(\%)$ \\
\hline Age (mean, SD) & $36.4(12.1)$ & $35.8(11.0)$ & $34.7(11.2)$ & & $35.2(11.5)$ & $39.8(11.3)$ & $33.9(12.3)$ & \\
\hline \multicolumn{9}{|l|}{ Age group (years) } \\
\hline$<19$ & $32(4.9)$ & $17(3.1)$ & $19(3.5)$ & $68(3.9)$ & $23(5.5)$ & $18(3.1)$ & $30(5.4)$ & $71(4.5)$ \\
\hline $20-29$ & $196(29.8)$ & 164 (29.9) & $200(36.4)$ & $560(31.8)$ & $136(32.3)$ & $104(17.8)$ & $225(40.8)$ & 465 (29.9) \\
\hline $30-39$ & $185(28.1)$ & $173(31.1)$ & $150(27.3)$ & $508(28.8)$ & $124(29.4)$ & $160(27.4)$ & $129(23.4)$ & $413(26.5)$ \\
\hline $40-49$ & $114(17.3)$ & $122(21.9)$ & $105(19.1)$ & $341(19.3)$ & $77(18.3)$ & $171(29.3)$ & 77 (13.9) & $325(20.9)$ \\
\hline $50+$ & $131(19.9)$ & $80(14.4)$ & $75(13.7)$ & $286(16.2)$ & $61(14.5)$ & $131(22.4)$ & $91(16.5)$ & $283(18.2)$ \\
\hline \multicolumn{9}{|l|}{ Education } \\
\hline Primary or less & $224(34.0)$ & $446(80.2)$ & $238(43.4)$ & $908(51.5)$ & $90(21.4)$ & $380(65.3)$ & $228(41.3)$ & $698(44.9)$ \\
\hline Secondary or more & $434(66.0)$ & $110(19.8)$ & $310(56.6)$ & $854(48.5)$ & $330(78.6)$ & $202(34.7)$ & $324(58.7)$ & $856(55.1)$ \\
\hline Missing & & & 1 & 1 & 1 & 2 & & 3 \\
\hline \multicolumn{9}{|l|}{ Religion } \\
\hline Roman Catholic & $58(8.8)$ & $157(28.8)$ & $12(2.2)$ & 227 (12.9) & $59(14.0)$ & $177(30.4)$ & $15(2.7)$ & $251(16.2)$ \\
\hline Protestant & $178(27.1)$ & $341(62.5)$ & $62(11.3)$ & $581(33.1)$ & $99(23.6)$ & $351(60.2)$ & $65(11.8)$ & $515(33.1)$ \\
\hline Pentecostal & $89(13.6)$ & $26(4.8)$ & $220(40.1)$ & $335(19.1)$ & $38(9.0)$ & $36(6.2)$ & $143(26.0)$ & $217(14.0)$ \\
\hline Apostolic Sect & $299(45.5)$ & $3(0.5)$ & $227(41.4)$ & $529(30.2)$ & $120(28.6)$ & $2(0.3)$ & $239(43.4)$ & $361(23.2)$ \\
\hline Other & $7(1.1)$ & $19(3.4)$ & $9(1.6)$ & $35(2.0)$ & $8(1.9)$ & $17(2.9)$ & $15(2.7)$ & $40(2.6)$ \\
\hline None & $27(4.1)$ & 0 & $19(3.4)$ & $46(2.6)$ & $96(22.9)$ & 0 & $74(13.4)$ & $170(10.9)$ \\
\hline Missing & & 10 & & 10 & 1 & 1 & 1 & 3 \\
\hline \multicolumn{9}{|l|}{ No. of years in community } \\
\hline$<1$ & $31(4.7)$ & $41(7.4)$ & $15(2.8)$ & $87(5.0)$ & $25(5.9)$ & $2(0.3)$ & $10(1.8)$ & $37(2.4)$ \\
\hline $1-5$ & $127(19.3)$ & $44(7.9)$ & $87(16.1)$ & $258(14.7)$ & $50(11.9)$ & $9(1.4)$ & $44(8.1)$ & $102(6.6)$ \\
\hline$>5$ & $500(76.0)$ & $471(84.7)$ & $437(81.1)$ & $1408(80.3)$ & $346(82.2)$ & $571(98.3)$ & $489(90.1)$ & $1406(91.0)$ \\
\hline Missing & & & 10 & 10 & & & & \\
\hline \multicolumn{9}{|c|}{ Away from home $>1$ month at a time in the past 12 months } \\
\hline Yes & $208(31.6)$ & $79(14.2)$ & $116(21.1)$ & $403(22.9)$ & $165(39.2)$ & $121(20.9)$ & $163(29.5)$ & 449 (28.9) \\
\hline No & $450(68.4)$ & 477 (85.9) & 433 (78.9) & $1360(77.1)$ & $256(60.8)$ & $459(79.1)$ & $389(70.5)$ & $1104(71.1)$ \\
\hline \multicolumn{9}{|l|}{ Marital status } \\
\hline Married/living together & $489(74.3)$ & $413(74.7)$ & $318(58.3)$ & $1220(69.5)$ & $292(69.5)$ & $504(86.3)$ & $235(42.8)$ & $1031(66.4)$ \\
\hline Never married & $30(4.5)$ & $35(6.3)$ & $183(33.6)$ & $248(14.1)$ & $100(23.8)$ & $61(10.5)$ & $293(53.4)$ & $454(29.2)$ \\
\hline Divorced/separated & $57(8.7)$ & $27(4.9)$ & $8(1.5)$ & $92(5.2)$ & $19(4.5)$ & $14(2.4)$ & $10(1.8)$ & $43(2.8)$ \\
\hline Widowed & $82(12.5)$ & $78(14.1)$ & $36(6.6)$ & $196(11.2)$ & $9(2.1)$ & $5(0.9)$ & $11(2.0)$ & $25(1.6)$ \\
\hline Missing & & 3 & 4 & 7 & 1 & & 3 & 4 \\
\hline No. in household (mean, median) & $5.34(2.46)$ & $5.87(6.00)$ & $6.50(6.00)$ & & $5.0(2.4)$ & $6.3(6.0)$ & $7.1(7.0)$ & \\
\hline \multicolumn{9}{|l|}{ Main source of income } \\
\hline Farming & $319(48.6)$ & $431(77.5)$ & $135(24.6)$ & $885(50.2)$ & $198(47.1)$ & $332(57.0)$ & $168(30.5)$ & $698(44.9)$ \\
\hline Formal employ & $26(3.9)$ & $28(5.0)$ & $55(10.0)$ & $109(6.2)$ & $54(12.9)$ & $78(13.4)$ & $70(12.7)$ & $202(13.0)$ \\
\hline Informal employ & $161(24.5)$ & $54(9.7)$ & $154(28.1)$ & 369 (20.9) & $130(31.0)$ & $132(22.6)$ & $166(30.1)$ & $428(27.5)$ \\
\hline No work, receive money from others & $144(21.9)$ & $27(4.9)$ & $205(37.3)$ & $376(21.3)$ & $36(8.6)$ & $17(2.9)$ & $146(26.5)$ & 199 (12.8) \\
\hline Other & $7(1.1)$ & $16(2.9)$ & 0 & $23(1.3)$ & $2(0.5)$ & $24(4.1)$ & $1(0.2)$ & $27(1.7)$ \\
\hline Missing & 1 & 0 & 0 & 1 & 1 & 1 & 1 & 3 \\
\hline
\end{tabular}

1 (community leader engagement intervention only). For both men and women, adding peer groups led to significant improvements in the $\mathrm{MCH}$ beliefs score (arm 3 vs. arm 2) $(\mathrm{p}<0.05)$. However, the GEM score did not change significantly with the addition of the peer groups. For both men and women, the community days and peer group interventions (arms 2 and 3) did not lead to significantly 
Table 3 Indicators scores by study arm and gender, all countries combined

All countries combined

Difference (t-test) between pre- $\mathrm{P}$ value post intervention $(95 \% \mathrm{CI})$

Women

$\mathrm{MCH}$ beliefs score

Arm 1

$1.21(0.81,1.60)$

Arm 2

$1.72(1.30,2.14)$

Arm 3

$2.54(2.11,2.98)$

$<0.001$

$<0.001$

$<0.001$

Stigma score

Arm 1

$-1.01(-1.46,-0.55)$

Arm 2

$-1.00(-1.43,-0.56)$

$<0.001$

Arm 2

$-1.30(-1.72,-0.88)$

$<0.001$

$<0.001$

Gender equitable score

Arm 1

$1.27(0.65,1.90)$

Arm 2

$2.59(2.00,3.18)$

Arm 3

$1.88(1.28,2.47)$

$<0.001$

$<0.001$

$<0.001$

Men

MCH beliefs score

Arm 2

$1.69(1.23,2.16)$

$<0.001$

Arm 3

$2.93(2.43,3.42)$

$<0.001$

Stigma score

Arm 1

Arm 2

$-0.61(-1.08,-0.15)$

0.010

$-1.14(-1.62,-0.65)$

$<0.001$

Arm 3

-1.21 (- 1.69, - 0.74)

$<0.001$

Gender equitable score

Arm 1

$0.36(-0.34,1.06)$

0.31

Arm 2

$1.73(1.07,2.39)$

Arm 3

$1.15(0.49,1.81)$

$<0.001$

0.0007

Adjusted for country, age and education

The significance level was defined as $p<0.05$

greater improvements in the stigma score, when compared with arm 1(community leader engagement only).

When stratifying these results by country, the combined intervention arms (2 and 3) showed score improvements, for both men and women, for two of the three outcomes (Table 5). However, this improvement is mainly seen for mean community $\mathrm{MCH}$ scores and mean stigma scores for two out of the three countries. The only country to have significant improvements in mean GEM scores from the combined interventions for both men and women was Uganda $(\mathrm{p}<0.01)$. The combined intervention improved GEM scores significantly among women in Zimbabwe and Eswatini $(p<0.01)$, but not among the men. However, similar to the combined country analysis, the addition of the peer group intervention in arm 3 led to improvements in mean $\mathrm{MCH}$ beliefs scores, compared to arm 2, for most of the groups studied $(p<0.05)$. However, the peer group intervention did lead to significant improvements in mean stigma scores for most groups across all three countries $(p<0.01)$.

Women in arm 3 had significantly greater improvements in mean outcomes scores than the women in arm 1 in Zimbabwe and Uganda. For women in Zimbabwe, those in arm 3 had greater increases in mean MCH beliefs score (diff $=1.15, \mathrm{p}=0.012$ ) than those in arm 1. Among women in Uganda, those in arm 3 had a greater increase in mean $\mathrm{MCH}$ beliefs score $(\mathrm{diff}=1.71, \mathrm{p}=0.0009)$, greater reduction in mean HIV stigma score (diff $=-2.129, \mathrm{p}<0.0001$ ), and greater increase in mean gender equitable norms score (diff $=2.741, \mathrm{p}<0.0001)$ than those in arm 1 .

Among the men, the results were more varied. In Uganda, however, men in arm 3 had a significantly greater increase in mean MCH beliefs score $(\mathrm{p}<0.0001)$, greater decrease in mean HIV stigma score $(\mathrm{p}<0.0001)$, and greater increase in mean GEM scores $(\mathrm{p}<0.0001)$ than men in arm 1.

\section{Discussion}

In this rural population, the results show that for both women and men, arm 2 (community leader engagement plus community days), and arm 3 (community leader engagement, community days, and peer groups) led to greater mean score changes than that of arm 1 (community leader engagement only), for at least two of the three outcome scores. These interventions led to the intended changes in $\mathrm{MCH}$ beliefs, HIV stigma, and gender equitable norms among women in the countries studied. However, because both men and women were intentionally included in all three interventions, mean score improvements were seen among the men as well.

Table 4 Difference (t-test) in indicator mean score changes pre- vs post-intervention between study arms by gender

\begin{tabular}{|c|c|c|c|c|c|c|c|c|c|}
\hline & \multicolumn{3}{|c|}{ MCH Beliefs Score } & \multicolumn{3}{|c|}{ HIV Stigma score } & \multicolumn{3}{|c|}{ Gender-equitable score } \\
\hline & Arm 2 vs 1 & Arm 3 vs 1 & Arm 3 vs 2 & Arm 2 vs 1 & Arm 3 vs 1 & Arm 3 vs 2 & Arm 2 vs 1 & Arm 3 vs 1 & Arm 3 vs 2 \\
\hline Women & $\begin{aligned} \text { Diff } & =0.52 \\
p & =0.079\end{aligned}$ & $\begin{array}{l}\text { Diff }=1.34 \\
p<0.0001\end{array}$ & $\begin{aligned} \text { Diff } & =0.82 \\
p & =0.006\end{aligned}$ & $\begin{aligned} \text { Diff } & =0.008 \\
p & =0.98\end{aligned}$ & $\begin{array}{c}\text { Diff }=-0.29 \\
p=0.35\end{array}$ & $\begin{array}{c}\text { Diff }=-0.30 \\
p=0.34\end{array}$ & $\begin{aligned} \text { Diff } & =1.32 \\
p & =0.002\end{aligned}$ & $\begin{aligned} \text { Diff } & =0.60 \\
p & =0.16\end{aligned}$ & $\begin{aligned} \text { Diff } & =-0.72 \\
p & =0.099\end{aligned}$ \\
\hline Men & $\begin{aligned} \text { Diff } & =0.79 \\
p & =0.018\end{aligned}$ & $\begin{array}{l}\text { Diff }=2.03 \\
p<0.0001\end{array}$ & $\begin{aligned} \text { Diff } & =1.23 \\
p & =0.0003\end{aligned}$ & $\begin{aligned} \operatorname{Diff} & =-0.52 \\
p & =0.13\end{aligned}$ & $\begin{array}{c}\text { Diff }=-0.60 \\
p=0.083\end{array}$ & $\begin{aligned} \text { Diff } & =-0.079 \\
p & =0.82\end{aligned}$ & $\begin{aligned} \text { Diff } & =1.37 \\
p & =0.004\end{aligned}$ & $\begin{aligned} \text { Diff } & =0.79 \\
p & =0.11\end{aligned}$ & $\begin{aligned} \text { Diff } & =-0.58 \\
p & =0.24\end{aligned}$ \\
\hline
\end{tabular}

Adjusted for country, age and education 
Table 5 Changes in mean indicator scores by study arm, country and gender

\begin{tabular}{|c|c|c|c|c|}
\hline \multirow[t]{2}{*}{ Study arms } & \multicolumn{2}{|l|}{ Women } & \multicolumn{2}{|l|}{ Men } \\
\hline & $\begin{array}{l}\text { Difference pre-post inter- } \\
\text { vention }(95 \% \mathrm{CI})\end{array}$ & $\mathrm{p}$-value & $\begin{array}{l}\text { Difference pre-post inter- } \\
\text { vention }(95 \% \mathrm{CI})\end{array}$ & p-value \\
\hline \multicolumn{5}{|l|}{ Zimbabwe } \\
\hline \multicolumn{5}{|c|}{ MCH beliefs score } \\
\hline Study arm 1 & $2.86(2.25,3.47)$ & $<.00001$ & $2.60(1.69,3.51)$ & $<0.0001$ \\
\hline Study arm 2 & $4.16(3.52,4.79)$ & $<0.0001$ & $3.56(2.71,4.40)$ & $<0.0001$ \\
\hline Study arm 3 & $4.01(3.34,4.68)$ & $<.00001$ & $3.78(2.97,4.59)$ & $<0.0001$ \\
\hline \multicolumn{5}{|l|}{ Stigma score } \\
\hline Study arm 1 & $-2.24(-2.85,-1.63)$ & $<0.0001$ & $-1.44(-2.27,-0.61)$ & 0.0008 \\
\hline Study arm 2 & $-1.56(-2.18,-0.94)$ & $<.00001$ & $-2.33(-3.11,-1.54)$ & $<0.0001$ \\
\hline Study arm 3 & $-1.38(-2.03,-0.72)$ & $<.00001$ & $-0.77(-1.64,0.09)$ & 0.0803 \\
\hline \multicolumn{5}{|l|}{ GEM score } \\
\hline Study arm 1 & $1.28(0.39,2.16)$ & 0.0044 & $1.01(-0.21,2.23)$ & 0.1032 \\
\hline Study arm 2 & $2.13(1.23,3.02)$ & $<0.0001$ & $1.83(0.70,2.95)$ & 0.0015 \\
\hline Study arm 3 & $0.29(-0.62,1.21)$ & 0.5267 & $0.89(-0.24,2.04)$ & 0.1228 \\
\hline \multicolumn{5}{|l|}{ Uganda } \\
\hline \multicolumn{5}{|c|}{$\mathrm{MCH}$ beliefs score } \\
\hline Study arm 1 & $-0.83(-1.49,-0.17)$ & 0.0142 & $-0.54(-1.24,0.16)$ & 0.1313 \\
\hline Study arm 2 & $-0.21(-0.94,0.52)$ & 0.5731 & $0.26(-0.51,1.01)$ & 0.5099 \\
\hline Study arm 3 & $0.88(0.17,1.58)$ & 0.0153 & $2.83(2.08,3.58)$ & $<0.0001$ \\
\hline \multicolumn{5}{|l|}{ Stigma score } \\
\hline Study arm 1 & $-0.37(-0.98,0.25)$ & 0.2391 & $-0.23(-0.82,0.36)$ & 0.4385 \\
\hline Study arm 2 & $-1.49(-2.21,-0.77)$ & $<0.0001$ & $-1.41(-2.07,-0.76)$ & $<0.0001$ \\
\hline Study arm 3 & $-2.49(-3.26,-1.74)$ & $<0.0001$ & $-2.38(-3.08,-1.67)$ & $<0.0001$ \\
\hline \multicolumn{5}{|l|}{ GEM score } \\
\hline Study arm 1 & $-1.30(-2.10,-0.51)$ & 0.0014 & $-1.90(-2.83,-0.98)$ & $<0.0001$ \\
\hline Study arm 2 & $2.19(1.39,3.00)$ & $<0.0001$ & $1.01(0.15,1.87)$ & 0.0215 \\
\hline Study arm 3 & $1.52(0.70,2.34)$ & 0.0003 & $1.42(0.55,2.29)$ & 0.0014 \\
\hline \multicolumn{5}{|l|}{ Eswatini } \\
\hline \multicolumn{5}{|c|}{$\mathrm{MCH}$ beliefs score } \\
\hline Study arm 1 & $1.16(0.46,1.87)$ & 0.0013 & $1.24(0.47,1.99)$ & 0.0015 \\
\hline Study arm 2 & $0.59(-0.14,1.33)$ & 0.1137 & $1.67(0.91,2.43)$ & $<0.0001$ \\
\hline Study arm 3 & $1.75(1.05,2.44)$ & $<0.0001$ & $1.71(0.85,2.58)$ & 0.0001 \\
\hline \multicolumn{5}{|l|}{ Stigma score } \\
\hline Study arm 1 & $0.58(0.00,1.18)$ & 0.0492 & $-0.33(-0.95,0.29)$ & 0.3001 \\
\hline Study arm 2 & $0.60(-0.00,1.21)$ & 0.0514 & $0.26(-0.39,0.93)$ & 0.4337 \\
\hline Study arm 3 & $-0.23(-0.78,0.32)$ & 0.4158 & $-0.58(-1.29,0.12)$ & 0.1040 \\
\hline \multicolumn{5}{|l|}{ GEM score } \\
\hline Study arm 1 & $2.10(1.24,2.96)$ & $<0.0001$ & $1.77(0.95,2.59)$ & $<0.0001$ \\
\hline Study arm 2 & $1.31(0.53,2.08)$ & 0.0010 & $1.94(1.07,2.81)$ & $<0.0001$ \\
\hline Study arm 3 & $1.52(0.70,2.34)$ & 0.0003 & $0.59(-0.39,1.59)$ & 0.2386 \\
\hline
\end{tabular}

Adjusted for age and education

The significance level was defined as $p<0.05$
This showed an increase in MCH beliefs, reduction in HIV stigma, and increased gender equitable norms among men. This is a desirable secondary outcome, as men's increased $\mathrm{MCH}$ and PMTCT beliefs and knowledge, reduced HIV stigma, and increased gender equitable norms could lead to more male involvement in $\mathrm{MCH}$ and PMTCT issues.
Overall, the educational interventions seemed to be effective for all study arms, with greater improvements in outcomes for the cumulative interventions. These educational interventions could potentially reduce the MTCT rate by increasing MCH beliefs, reducing HIV-related stigma, and encouraging gender equitable norms. 
Although there were some differences between the country-by-country and combined analysis results, they both showed that the combined interventions (arms 2 and 3) were more effective than the community leader engagement intervention alone (arm 1), for both women and men. Some of the country differences may have been due to the socioeconomic and demographic differences. Due to the setting, the Ugandan population was less educated, and more traditional, while the population in Eswatini was generally younger, and the Zimbabwean population was the most educated.

Unlike the community leader engagement intervention, the community days and peer group interventions were targeted towards individuals in smaller groups. In the community days, individuals were encouraged to test for HIV and get HIV counseling. In the peer groups, individuals were educated about gender-based violence, safe sex practices, ANC, and PMTCT. This suggests that individuals may be more likely to address their health behaviors regarding HIV prevention and PMTCT when given the chance to discuss these issues in small groups. Other studies have also shown the positive effects of small group and peer interventions on health behaviors regarding HIV prevention behavior and attitudes [16-18].

There were several advantages to the design and analysis of this study. The study of the interventions was done in the form of a randomized trial. This study design controlled for confounding factors, such as demographic variables. Furthermore, it minimized the effect of these confounding factors on the exposure and outcome variables. The sample used for the study was representative of the population.

In addition, the specific targeting of men as important players in MCH likely accounted for the level of change seen at the community level. Since the interventions were designed to improve $\mathrm{MCH}$ knowledge and gender-equitable norms in the community, the study was able to reach a much broader audience than it would have if it had focused only on HIV-positive women and men.

However, there were limitations to this study design as well. Generalization of the results of this study may be limited to only EGPAF-supported regions or districts, since results differed by country and gender. The pre-/post-intervention assessment design may also be prone to confounding by temporal changes that could have occurred between assessments. In addition, the fact that this was a serial cross-sectional study, rather than a longitudinal study, limits the analytical methods that could be used. The low Cronbach's alpha scores for MCH beliefs, which suggest low reliability of the measures, could be related to the low number of items in the scales, as well as the fact that the measures used were part of a questionnaire that had number of other questions. The t-test was the most optimal option for analyzing the outcome in this study. An advantage of the t-test was that it allowed for a simple comparison of pre- vs. post-intervention changes in scores for each study arm.
However, the t-test did not account for potential demographic confounders. To account for this, t-tests were used to compare mean score changes among demographic categories, but generalized linear models were also used to compare mean score changes between study arms. Therefore, having demographic $\mathrm{t}$-tests, as well as generalized linear model analysis, accounted for the limitations of the initial t-tests. The generalized linear model analysis accounted for potential clustering of participants through inclusion of random effects in the model.

\section{Conclusion}

Arm 3, which combined all three interventions and arm 2 (community leader engagement and community days) led to improvements in outcome scores, compared to the community leader engagement intervention along (arm 1). This suggests that a package of community interventions may be most effective in increasing community HIV knowledge and improving gender equitable norms.

Acknowledgements This study was supported by the Department of Foreign Affairs, Trade and Development Canada. The authors would like to acknowledge the study participants in various countries. We would also like to acknowledge Dr. Irene Kuo, of the Milken Institute of Public Health of the George Washington University, and Shannon Viana, Adrienne Hayes and Nicole Herrera of EGPAF, and Jenny and A. Edwin Herrera. Dr. Kuo assisted Natasha Bandopadhay in the analysis and reporting on this project, and Shannon Viana and Adrienne Hayes edited and formatted the manuscript. Nicole Herrera translated the abstract into Spanish, and Jenny and A. Edwin Herrera reviewed the translation. The Project ACCLAIM Study Group: Godfrey Woelk, Mary Pat Kieffer, Dephine Mpofu, Caspian Chouraya, Kwashie Kudiabor, Philisiwe Khumalo, Edward Bitarakwate, Eliab Natumanya Kajungu, Agnes Mahomva, Reuben Musarandega.

Author Contributions NB analyzed the data and wrote the first draft. GW, MPK, and DM contributed to the study concept and design, drafting, and editing of this manuscript. All authors read and approved the final version of the manuscript.

\section{Compliance with Ethical Standards}

Conflict of interest All authors affirm that they have no competing financial interests to declare.

Ethical Approval The study protocol was reviewed and approved by Institutional Review Boards in the three countries: the Medical Research Council of Zimbabwe (MRCZ), the Swaziland Scientific and Ethics Committee (SEC), and the Uganda National Council on Science and Technology (UNCST) National HIV/AIDS Research Committee (NARC).

Informed Consent Survey participants in both the pre- and post-intervention surveys provided written informed consent for interview on explanation of the study nature and purpose.

Open Access This article is licensed under a Creative Commons Attribution 4.0 International License, which permits use, sharing, adaptation, distribution and reproduction in any medium or format, as long 
as you give appropriate credit to the original author(s) and the source, provide a link to the Creative Commons licence, and indicate if changes were made. The images or other third party material in this article are included in the article's Creative Commons licence, unless indicated otherwise in a credit line to the material. If material is not included in the article's Creative Commons licence and your intended use is not permitted by statutory regulation or exceeds the permitted use, you will need to obtain permission directly from the copyright holder. To view a copy of this licence, visit http://creativecommons.org/licenses/by/4.0/.

\section{References}

1. UNAIDS. 2015 Progress report on the global plan towards the elimination of new HIV infections among children and keeping their mothers alive. Joint United Nations Programme on HIV/ AIDS. Geneva: UNAIDS; 2016.

2. WHO. WHO HIV update: global epidemic, progress in scale up and policy uptake. Geneva: World Health Organization (WHO); 2019.

3. Buregyeya E, Naigino R, Mukose A, Makumbi F, Esiru G, Arinaitwe $\mathrm{J}$, et al. Facilitators and barriers to uptake and adherence to lifelong antiretroviral therapy among HIV infected pregnant women in Uganda: a qualitative study. BMC Pregnancy Childbirth. 2017;17:94.

4. Cataldo F, Chiwaula L, Nkhata M, van Lettow M, Kasende F, Rosenberg NE, et al. Exploring the experiences of women and health care workers in the context of PMTCT option B plus in Malawi. J Acquir Immune Defic Syndr. 2017;74(5):517-22.

5. Elwell K. Facilitators and barriers to treatment adherence within PMTCT programs in Malawi. AIDS Care. 2016;28(8):971-5.

6. Gunn JKL, Asaolu IO, Center KE, Gibson SJ, Wightman P, Ezeanolue EE, et al. Antenatal care and uptake of HIV testing among pregnant women in sub-Saharan Africa: a cross-sectional study. J Int AIDS Soc. 2016;19(1):20605.

7. Brusamento S, Ghanotakis E, Car LT, van Velthoven MH, Majeed A, Car J. Male involvement for increasing the effectiveness of prevention of mother-to-child HIV transmission (PMTCT) programmes. Cochrane Database Syst Rev. 2012;10:CD009468.

8. Hlarlaithe MO, Grede N, de Pee S, Bloem M. Economic and social factors are some of the most common barriers preventing women from accessing maternal and newborn child health $(\mathrm{MNCH})$ and prevention of mother-to-child transmission (PMTCT) services: a literature review. AIDS Behav. 2014;18(Suppl 5):S516-30.

9. DiCarlo A, Fayorsey R, Syengo M, Chege D, Sirengo M, Reidy W, et al. Lay health worker experiences administering a multi-level combination intervention to improve PMTCT retention. BMC Health Serv Res. 2018;18(1):17.
10. Woelk GB, Kieffer MP, Walker D, Mpofu D, Machekano R, Project ACCLAIM study group. Evaluating the effectiveness of selected community-level interventions on key maternal, child health, and prevention of mother-to-child transmission of HIV outcomes in three countries (the ACCLAIM project): a study protocol for a randomized controlled trial. Trials. 2016. https://doi. org/10.1186/s13063-016-1202-y.

11. Pulerwitz J, Barker G. Measuring attitudes toward gender norms among young men in Brazil: development and psychometric evaluation of the GEM Scale. Men Masculinities. 2008;10:322-38. https://doi.org/10.1177/1097184X06298778.

12. The Synergy Project. Working report measuring HIV stigma: results of a field test in Tanzania. United States Agency for International Development, Contract HRN-C-00-99-00005-00, June 2005.

13. Krishna A, Shrade E. Cross-cultural measures of social capital: a tool and results from India and Panama. Washington, D.C.: World Bank; 2000.

14. Child Survival Technical Support/CORE Monitoring and Evaluation Working Group. Rapid knowledge, practices and coverage survey for PVO child survival. United States Agency for International Development, October 2000.

15. Treves-Kagan S, El Ayadi AM, Pettifor A, MacPhail C, Twine R, Maman S, et al. Gender, HIV testing and stigma: the Association of HIV Testing Behaviors and Community-Level and IndividualLevel Stigma in rural South Africa differ for men and women. AIDS Behav. 2017;21(9):2579-88.

16. Lifson AR, Workneh S, Hailemichael A, Demisse W, Slater L, Shenie T. Implementation of a peer HIV community support worker program in rural ethiopia to promote retention in care. J Int Assoc Provid AIDS Care (JIAPAC). 2016;16(1):75-80. https ://doi.org/10.1177/2325957415614648.

17. Kioko MT, Pertet AM. Factors contributing to antiretroviral drug adherence among adults living with HIV or AIDS in a Kenyan rural community. Afr J Prim Health Care \& Fam Med. 2017. https ://doi.org/10.4102/phcfm.v9i1.1343.

18. Etemadifar S, Bahrami M, Shahriari M, Farsani AK. The effectiveness of a supportive educative group intervention on family caregiver burden of patients with heart failure. Iran J Nurs Midwifery Res. 2014;19(3):217-23.

Publisher's Note Springer Nature remains neutral with regard to jurisdictional claims in published maps and institutional affiliations. 